\title{
Ischemic stroke risk, smoking, and the genetics of inflammation in a biracial population: the stroke prevention in young women study
} John W Cole*1,2, David W Brown ${ }^{3}$, Wayne H Giles ${ }^{3}$, Oscar C Stine ${ }^{4,5}$, Jeffrey R O'Connell ${ }^{4,5}$, Braxton D Mitchell ${ }^{4,5}$, John D Sorkin ${ }^{1,6}$, Marcella A Wozniak ${ }^{1,2}$, Barney J Stern ${ }^{1,2}$, Mary J Sparks ${ }^{2}$, Mark T Dobbins ${ }^{2}$, Latasha T Shoffner ${ }^{2}$, Nancy K Zappala ${ }^{2}$, Laurie J Reinhart ${ }^{5}$ and Steven J Kittner ${ }^{1,2}$

Address: ${ }^{1}$ Veterans Affairs Medical Center, Baltimore, Maryland, USA, 2Department of Neurology, University of Maryland School of Medicine, Baltimore, Maryland, USA, ${ }^{3}$ Centers for Disease Control, Atlanta, Georgia, USA, ${ }^{4}$ Department of Epidemiology and Preventive Medicine, University of Maryland School of Medicine, Baltimore, Maryland, USA, ${ }^{5}$ Department of Medicine, University of Maryland School of Medicine, Baltimore, Maryland, USA and ' ${ }^{6}$ niversity of Maryland School of Medicine Claude D. Pepper Older Americans Independence Center, Maryland, USA

Email: John W Cole* - jcole@som.umaryland.edu; David W Brown - dbrown6@cdc.gov; Wayne H Giles - hhwgo@cdc.gov;

Oscar C Stine - cstine@epi.umaryland.edu; Jeffrey R O'Connell - joconnel@medicine.umaryland.edu; Braxton D Mitchell - bmitchel@epi.umaryland.edu; John D Sorkin - jsorkin@grecc.umaryland.edu; Marcella A Wozniak - mwozniak@som.umaryland.edu; Barney J Stern - bstern@som.umaryland.edu; Mary J Sparks - msparks@som.umaryland.edu; Mark T Dobbins - mdobbins@som.umaryland.edu; Latasha T Shoffner - lshoffner@som.umaryland.edu; Nancy K Zappala - nzappala@som.umaryland.edu;

Laurie J Reinhart - lreinhar@medicine.umaryland.edu; Steven J Kittner - skittner@som.umaryland.edu

* Corresponding author

Published: 26 August 2008

Thrombosis Journal 2008, 6:II doi:10.1186/1477-9560-6-1I
Received: 26 March 2008

Accepted: 26 August 2008

This article is available from: http://www.thrombosisjournal.com/content/6/I/I I

(c) 2008 Cole et al; licensee BioMed Central Ltd.

This is an Open Access article distributed under the terms of the Creative Commons Attribution License (http://creativecommons.org/licenses/by/2.0), which permits unrestricted use, distribution, and reproduction in any medium, provided the original work is properly cited.

\begin{abstract}
Background: Although cigarette smoking is a well-established risk factor for vascular disease, the genetic mechanisms that link cigarette smoking to an increased incidence of stroke are not well understood. Genetic variations within the genes of the inflammatory pathways are thought to partially mediate this risk. Here we evaluate the association of several inflammatory gene single nucleotide polymorphisms (SNPs) with ischemic stroke risk among young women, further stratified by current cigarette smoking status.
\end{abstract}

Methods: A population-based case-control study of stroke among women aged 15-49 identified 224 cases of first ischemic stroke (47.3\% African-American) and $21 \mathrm{I}$ age-comparable control subjects (43.1\% African-American). Several inflammatory candidate gene SNPs chosen through literature review were genotyped in the study population and assessed for association with stroke and interaction with smoking status.

Results: Of the 8 SNPs (across 6 genes) analyzed, only IL6 SNP rs2069832 (allele C, AfricanAmerican frequency $=92 \%$, Caucasian frequency $=55 \%$ ) was found to be significantly associated with stroke using an additive model, and this was only among African-Americans (age-adjusted: OR $=2.2,95 \% \mathrm{Cl}=1.0-5.0, \mathrm{p}=0.049$; risk factor adjusted: $\mathrm{OR}=2.5,95 \% \mathrm{Cl}=1.0-6.5, \mathrm{p}=0.05)$. When stratified by smoking status, two SNPs demonstrated statistically significant geneenvironment interactions. First, the T allele (frequency $=5 \%$ ) of IL6 SNP rs2069830 was found to 
be protective among non-smokers $(\mathrm{OR}=0.30,95 \% \mathrm{Cl}=0 . \mathrm{II}-.082, \mathrm{p}=0.02$ ), but not among smokers $(\mathrm{OR}=1.63,95 \% \mathrm{Cl}=0.48-5.58, \mathrm{p}=0.43)$; genotype by smoking interaction $(\mathrm{p}=0.036)$. Second, the $C$ allele (frequency $=39 \%$ ) of CD / 4 SNP rs 2569190 was found to increase risk among smokers $(\mathrm{OR}=2.05,95 \% \mathrm{Cl}=1.09-3.86, \mathrm{p}=0.03)$, but not among non-smokers $(\mathrm{OR}=0.93,95 \%$ $\mathrm{Cl}=0.62-\mathrm{I} .39, \mathrm{p}=0.72)$; genotype by smoking interaction $(\mathrm{p}=0.039)$.

Conclusion: This study demonstrates that inflammatory gene SNPs are associated with earlyonset ischemic stroke among African-American women (IL6) and that cigarette smoking may modulate stroke risk through a gene-environment interaction (IL6 and CD/4). Our finding replicates a prior study showing an interaction with smoking and the $C$ allele of CD/4 SNP rs2569190.

\section{Introduction}

Cigarette smoking is a well-established risk factor for vascular disease and stroke. Various mechanisms that link cigarette smoking to these risks have been described, including: vasomotor dysfunction [1-3] modification of the lipid profile (notably increased oxidation of LDL) $[1,2,4]$, modification of prothrombotic effects, including altered platelet function $[2,5]$, and deregulation of antithrombotic, prothrombotic, and fibrinolytic mechanisms $[1,2]$. The final common pathway shared by these mechanisms is heightened inflammation, which is also considered a potential risk mechanism $[1,2,6]$. Each of the mechanisms is under the influence of multiple genes, therefore an individuals' susceptibility to the detrimental effects of cigarette smoke appears to be related to their pro-inflammatory versus anti-inflammatory gene-specific allele load. This hypothesis is supported by multiple studies that indicate pro-inflammatory gene-specific allele load is associated with enhanced inflammation and early atherosclerosis in smokers [7-10]. Many inflammatory genes have been implicated in these relationships, specific to this study these include: interleukin-1A (IL1A; OMIM 147760), interleukin-1 receptor - type I precursor (IL1R1; OMIM 147810), interleukin-1B (IL1B; OMIM 147720), interleukin-6 (ILG; OMIM 147620), stromelysin-1 (MMP3; OMIM 185250), and monocyte endotoxin receptor (CD14; OMIM 158120). In this study, we analyze the relationships between various polymorphisms of these genes, ischemic stroke risk, and smoking status.

\section{Research design and methods Study subjects}

The Stroke Prevention in Young Women Study 2 (SPYW2) is a population-based case-control study that was designed to examine genetic risk factors for ischemic stroke in young women. The term "population-based" indicates that the cases and the comparison control group were identified from the same population including all of Maryland (except the far Western panhandle), Washington DC, and the southern portions of both Pennsylvania and Delaware. Two hundred thirty nine female cases age 15 to 49 years of age with a first cerebral infarction were identified by discharge surveillance at 51 regional hospitals and through direct referral by regional neurologists. The methods for discharge surveillance, chart abstraction, and case adjudication have been described previously [1113]. We determined each subject's case-control status (i.e. determined subjects who had a stroke) blinded to genetic information. Strokes were classified as having a probable, possible or undetermined etiology [11,12]. Using predetermined exclusion criteria, modified from the Siblings With Ischemic Stroke Study (SWISS) protocol [14], we excluded 15 cases with the following characteristics: sickle cell disease $(\mathrm{n}=1)$, CNS vasculitis by angiogram and clinical criteria $(\mathrm{n}=3)$, post-radiation arteriopathy $(\mathrm{n}=1)$, endocarditis $(n=3)$, neurosyphillis $(n=1)$, mechanical prosthetic heart valves $(n=2)$, left atrial myxoma $(n=1)$, and cocaine use in the 48 hours prior to their stroke $(\mathrm{n}=$ 3 ). Controls subjects (212 women without a history of stroke), were identified by random digit dialing and were frequency matched to the cases by age and geographic region of residence. One control was excluded from analyses based on a history of sickle cell disease. Thus, the sample for genetic analyses consisted of 224 cases and 211 controls.

Cases and controls were grouped into the following raceethnic categories: Caucasian (non-Hispanic) (95 cases and 99 controls), African-American (105 cases and 91 controls), and other (including Hispanic, Asian, American-Indian, etc.) (24 cases and 21 controls). Because of the small size and heterogeneity of the latter group, it was not analyzed separately, but was included within the combined total study group (224 cases and 211 controls). Strokes were further classified by subtype: the atherosclerotic group included 27 cases with either probable or possible atherosclerotic mechanism, the cardiac group included 14 cases with a probable cardiac source of embolism, the probable dissection group included 13 cases confirmed by neuroimaging, the lacunar group included 45 cases of symptomatic small deep lesions on neuroimaging studies or classic lacunar syndromes regardless of other potential causes, and the probable hematologic group included 9 cases. These categories were not mutu- 
ally exclusive. There were 125 non-lacunar stroke cases of undetermined etiology.

\section{Single Nucleotide Polymorphisms (SNPs) evaluated}

We identified genes and SNPs that influence inflammation through a literature review seeking an association of the genes and SNPs with vascular disease (stroke, myocardial infarction, peripheral vascular disease, or atherosclerosis). If the evidence suggested that smoking might modify the relationship between gene or SNP and stroke through a gene-environment interaction, a higher priority for inclusion in our analyses was assigned to that gene or SNP. Because we sought to evaluate common SNPs, only those SNPs with a minor allele frequency of 0.05 or greater among African-Americans or Caucasians as per the NCBI SNP website http://www.ncbi.nlm.nih.gov/entrez/ query.fcgi? $\mathrm{CMD}=$ search $\& \mathrm{DB}=\mathrm{snp}$ were evaluated. After weighing these considerations, the final list of genes and SNPs analyzed in this study included: CD14 (rs2569190), IL1A (rs17561), IL1R1 (rs3917318), IL1B (rs3917365), IL6 (rs1800797, rs2069830, 2069832), and MMP3 (rs679620).

\section{Genotyping methods for the case/control population} Genotyping was conducted on DNA isolated from whole blood using the QIAamp DNA Blood Maxi Kit (Qiagen, Valencia, CA). SNP genotyping was performed by one of two methods. The first method, developed for a SNP stream Ultra-High Throughput machine (Beckman Coulter, Inc., Fullerton, CA) is capable of genotyping up to 12SNPs simultaneously. Sequences surrounding the SNPs were obtained from GenBank http:// www.ncbi.nlm.nih.gov/Genbank/index.html and submitted to Autoprimer.com (Beckman Coulter, Inc.). For each SNP, three primers were designed, two for PCR amplification and an internal primer with a $5^{\prime}$ DNA sequence tag. Pairs of primers were used to initiate PCR amplification. The free primers were removed by enzymatic digestion using Exonuclease I and Shrimp Alkaline Phosphotase (Beckman Coulter, Inc.). The internal primers were used to initiate a sequencing reaction that adds one labeled base for the alternative nucleotides of each SNP to have distinct labels. The labeled products are separated on a SNP-IT plate consisting of 384 mini-arrays with 16-spots each (Beckman Coulter, Inc.). For each individual DNA sample, 16 spots hybridized to the two homozygotes, the heterozygote, a negative control and the 12-labeled primers associated with the 12-SNPs. Thus, every PCR and labeling reaction had internal controls to confirm the success of the reactions and the appropriateness of the fluorescent outputs for each DNA sample. SNPs genotyped using this method include: IL1R1 (rs3917318); IL1B (rs3917365); IL6 (rs1800797, 2069832).
The second genotyping method was Taqman (Applied Biosystems). This method is based on four primers, two flanking the SNP that are used to amplify the DNA surrounding the SNP and two, one for each alternative allele, that were labeled with different fluorescent dyes. The original form of the labeled primer has a quencher in close proximity to the dye. However, when the exonuclease activity of DNA polymerase disrupts the primer hybridized to the single strand DNA during the PCR, then quencher and the dye are released and the fluorescence can be measured. The reaction itself follows manufacturer's instructions included with each individual primer set. SNPs genotyped using this method include: CD14 (rs2569190); IL1A (rs17561); IL6 (rs2069830); MMP3 (rs679620).

\section{Analyses}

All statistical analyses were performed using SAS ${ }^{\circledast}$, Version 9.1 (SAS Institute, Cary, NC). We compared means by two-sided t-tests and proportions by $\chi^{2}$ tests. All SNPs were verified to be in Hardy-Weinberg equilibrium. Adjusted odds ratios from logistic regression were used to determine whether the presence of the risk allele was associated with an increased risk for ischemic stroke after controlling for potential confounders.

Two additive models were used to determine the relation between SNP and outcome. The first model (our primary analyses) was adjusted for age and race (when all subjects were included in the analysis) or only age when the analysis was stratified by race (i.e. African-Americans and Caucasians). The second model, (adjusted model) added history of hypertension, diabetes, smoking, oral contraceptive (OCP) use and angina pectoris or myocardial infarction (angina-MI), to age (or age and race) to the independent variables used in the first model. The results of the analyses were expressed as odds ratios which quantify the increased risk of ischemic stroke associated with each additional risk allele. Age, race, current cigarette smoking status, and OCP use were determined by subject reports (or proxy report, if a participant was unable to answer). Hypertension and diabetes mellitus were determined by asking study participants (or a proxy) if a physician had ever told them they had the condition. Current smoking was defined as having one or more cigarettes in the month (31 days) preceding their stroke, or for controls, in the month prior to their interview. Current oral contraceptive use was also defined as use in the prior month.

In order to evaluate each SNP for a genotype by smoking interaction (as per our initial hypothesis), study participants were stratified by smoking status and evaluated in an age-, race-adjusted additive model. For those SNPs that demonstrated a potential genotype by smoking interac- 
tion the significance of the difference between the point estimates (i.e. the log odds ratios) in smokers and nonsmokers was tested using a z-test. Lastly, SNPs with significant z-test results were additionally evaluated for potential race-specific smoking interactions in an age-adjusted additive model, with the SNP stratified by smoking status further stratified by race (Caucasian and African-American).

In secondary analyses, significantly associated SNPs from the primary analyses (total population and race-stratified) underwent further analyses to evaluate groups stratified by other standard risk factors (age, hypertension, diabetes mellitus, OCP use, and history of angina/MI) and ischemic stroke subtype (atherosclerotic, cardiac, dissection, lacunar, hematologic, and stroke of unknown etiology (i.e. all other stroke)) with the later groups compared to all controls. Additionally, analyses consisting of dominant and recessive genetic models that included similar groups and covariates to the primary analyses were also performed. We did not adjust for multiple comparisons because our study was considered to be hypothesis generating.

\section{Results \\ Subject characteristics}

Demographic and risk factor characteristics by case-control status are described in Table 1 . The mean age of the cases was 41.7 years and the mean age of control subjects was 39.6 years. Cases were significantly more likely than controls to have a history of hypertension $(p<0.0001)$, diabetes ( $p=0.0002)$, angina-MI $(p=0.0005)$, to currently smoke cigarettes $(\mathrm{p}<0.0001)$, and to report the use of oral contraceptive pills (OCP) within the month prior to their stroke $(\mathrm{p}=0.032)$.

\section{Ischemic stroke risk}

Table 2 gives p-values for the age-adjusted additive model and risk factor-adjusted additive model for the eight SNPs stratified by race and case-control status, and also provides each SNPs location, allelic variants, and genotype call rate. Of the SNPs analyzed, only the IL6 SNP rs2069832 (C allele; overall frequency: African-Americans
$=92 \%$, Caucasians $=55 \%$ ) was found to be significantly associated with stroke, and this was only among AfricanAmericans (Age-adjusted model: $\mathrm{OR}=2.2,95 \% \mathrm{CI}=$ 1.0-5.0, $\mathrm{p}=0.049$; Risk Factor model: $\mathrm{OR}=2.5,95 \% \mathrm{CI}$ $=1.0-6.5, \mathrm{p}=0.05)$. Dominant and recessive models did not strengthen the association (data not shown). Stratifying participants by other risk factors and evaluating stroke risk in relation to SNP rs2069832 genotype revealed no associations with stroke (data not shown). Stratifying participants by stroke subtype as compared to all controls and evaluating stroke risk in relation to SNP rs2069832 genotype revealed no significant associations (data not shown).

\section{Ischemic stroke risk as stratified by smoking status}

Table 3 demonstrates the age- and race-adjusted additive model results for the SNPs stratified by smoking status. Two SNPs demonstrated a gene-environment interaction based upon smoking status. First, CD-14 SNP rs2569190 (C allele; frequency in total population $=39 \%$ ) was found to be associated with increased risk of stroke among smokers (OR $=2.05,95 \% \mathrm{CI}=1.09-3.87$, $\mathrm{p}=0.027$ ), but not non-smokers $(\mathrm{OR}=0.93,95 \% \mathrm{CI}=0.62-1.39, \mathrm{p}=$ $0.72)$. The two odds ratios were significantly different ( $\mathrm{p}$ = 0.039). Secondly, IL6 SNP rs2069830 (T allele; frequency in total population $=5 \%$ ) was found to be protective among non-smokers $(\mathrm{OR}=0.30,95 \% \mathrm{CI}=$ $0.11-.082, \mathrm{p}=0.02)$, but not among smokers $(\mathrm{OR}=1.63$, $95 \% \mathrm{CI}=0.48-5.58, \mathrm{p}=0.43)$. The two odds ratios were significantly different $(\mathrm{p}=0.036)$.

\section{Ischemic stroke risk as stratified by smoking status further stratified by race}

Results of the race-stratified smoking-genotype interaction analyses demonstrated no significant interactions. However, the race-stratified point estimates (ORs) remained similar to the combined population point estimates as detailed in the preceding paragraph. For CD-14 SNP rs2569190, similar ORs were seen among both smokers of both races (Caucasian OR $=2.21, \mathrm{p}=0.127$; African-American OR $=1.91, \mathrm{p}=0.143$ ) and non-smokers of both races (Caucasian OR $=1.18$, p = 0.60; AfricanAmerican $\mathrm{OR}=0.83, \mathrm{p}=0.55)$. For IL-6 SNP rs2069830,

Table I: Characteristics, by case-control status.

\begin{tabular}{cccc}
\hline & Cases (N = 224) & Controls (N = 2I I) & p-value \\
\hline Mean age (years) & 41.7 & 39.6 & 0.0026 \\
African-American (\%) & 47.3 & 43.1 & 0.579 \\
Hypertension (\%) & 41.1 & 14.2 & $<.0001$ \\
Diabetes mellitus (\%) & 17.9 & 6.2 & 0.0002 \\
Current smokers (\%) & 47.8 & 23.7 & $<.0001$ \\
Angina-MI (\%) & 11.6 & 2.8 & 0.0005 \\
OCP (\%) & 12.2 & 6.2 & 0.032 \\
\hline
\end{tabular}

* Two cases and one control could not recall their last OCP use, therefore cases $\mathrm{N}=222$ and controls $\mathrm{N}=210$. 
Table 2: Proinflammatory SNPs stratified by race and case/control status demonstrating allelic variants, genotype call rate, minor allele frequencies and p-values for age-adjusted additive model and risk factor adjusted additive model.

\begin{tabular}{|c|c|c|c|c|c|c|c|c|c|c|c|}
\hline \multirow[t]{3}{*}{ Gene } & \multirow{3}{*}{$\begin{array}{l}\text { SNP rs number, location and } \\
\text { function }\end{array}$} & \multirow[t]{3}{*}{ Alleles* } & \multirow[t]{3}{*}{ Call Rate (\%) } & \multicolumn{4}{|c|}{ African-Americans } & \multicolumn{4}{|c|}{ Caucasians } \\
\hline & & & & \multirow{2}{*}{$\begin{array}{c}\text { Cases } \\
\begin{array}{l}\text { Minor Allele } \\
\text { Frequency/N }\end{array}\end{array}$} & \multirow{2}{*}{\begin{tabular}{|c|} 
Controls \\
$\begin{array}{l}\text { Minor Allele } \\
\text { Frequency/N }\end{array}$
\end{tabular}} & \multicolumn{2}{|c|}{ p-value } & \multirow{2}{*}{$\begin{array}{c}\text { Cases } \\
\begin{array}{l}\text { Minor Allele } \\
\text { Frequency/N }\end{array}\end{array}$} & \multirow{2}{*}{\begin{tabular}{|c|} 
Controls \\
$\begin{array}{l}\text { Minor Allele } \\
\text { Frequency/N }\end{array}$
\end{tabular}} & \multicolumn{2}{|c|}{$p$-value } \\
\hline & & & & & & $\begin{array}{c}\text { Age- } \\
\text { adjusted }\end{array}$ & $\begin{array}{l}\text { Risk factor } \\
\text { adjusted** }\end{array}$ & & & Age-adjusted & $\begin{array}{l}\text { Risk factor } \\
\text { adjusted }\end{array}$ \\
\hline$C D / 4 \psi$ & rs2569190, 5' promotor & $\mathrm{C} / \mathrm{T}$ & $99 \%$ & $0.38 / 77$ & $0.42 / 62$ & 0.57 & 0.66 & $0.49 / 65$ & $0.40 / 75$ & 0.13 & 0.30 \\
\hline ILIA & rs 17561, exon 4 nonsynonymous & G/T & $98 \%$ & $0.18 / 102$ & $0.18 / 90$ & 0.83 & 0.73 & $0.27 / 93$ & $0.31 / 94$ & 0.32 & 0.80 \\
\hline ILIRI & rs 3917318 , intron 10 & $\mathrm{~A} / \mathbf{G}$ & $91 \%$ & $0.33 / 97$ & $0.29 / 88$ & 0.44 & 0.23 & $0.33 / 92$ & $0.36 / 92$ & 0.53 & 0.24 \\
\hline ILIB & rs3917365, 3' near gene & $\mathrm{C} / \mathrm{T}$ & $81 \%$ & $0.21 / 97$ & $0.17 / 83$ & 0.34 & 0.36 & $0.08 / 86$ & $0.08 / 89$ & 0.85 & 0.87 \\
\hline \multirow[t]{3}{*}{ IL6 } & rs $1800797,5^{\prime}$ near gene & A/G & $91 \%$ & $0.06 / 99$ & $0.10 / 88$ & 0.19 & 0.18 & $0.42 / 93$ & $0.43 / 91$ & 0.89 & 0.87 \\
\hline & rs 2069830 , exon 2 nonsynonymous & $\mathrm{C} / \mathrm{T}$ & $91 \%$ & $0.07 / 100$ & $0.09 / 87$ & 0.32 & 0.31 & $0.01 / 90$ & $0.03 / 93$ & 0.30 & 0.35 \\
\hline & rs 2069832 , intron 2 & $\mathrm{C} / \mathrm{T}$ & $89 \%$ & $0.05 / 97$ & $0.12 / 86$ & 0.049 & 0.05 & $0.45 / 92$ & $0.45 / 91$ & 0.97 & 0.85 \\
\hline MMP3 & rs679620, exon 2 nonsynonymous & $\mathrm{C} / \mathrm{T}$ & $89 \%$ & $0.35 / 103$ & $0.35 / 88$ & 0.95 & 0.72 & $0.45 / 90$ & $0.47 / 96$ & 0.85 & 1.0 \\
\hline
\end{tabular}

\%CD I 4 SNP rs 2569190 was genotyped in a smaller case-control sample $(\mathrm{N}=315)$.

** Risk factor adjusted - Additive model adjusted for age, hypertension, diabetes, oral contraceptive use, and angina-MI.

Table 3: Proinflammatory SNPs stratified by smoking status demonstrating the number of cases and controls, and Odds Ratio, $95 \% \mathrm{Cl}$ and p-values in an age-, race-adjusted additive model.

\begin{tabular}{|c|c|c|c|c|c|c|c|c|c|}
\hline \multirow[t]{2}{*}{ Gene } & \multirow[t]{2}{*}{ rs number } & \multicolumn{4}{|c|}{ Smokers } & \multicolumn{4}{|c|}{ Non-Smokers } \\
\hline & & Cases/Controls & OR* & $95 \% \mathrm{Cl}$ & p-value & Cases/Controls & OR* & $95 \% \mathrm{Cl}$ & p-value \\
\hline$C D / 4$ & rs2569190 & $77 / 31$ & 2.05 & $1.09-3.87$ & 0.027 & $82 / 121$ & 0.93 & $0.62-1.39$ & 0.72 \\
\hline ILIA & rsl756I & $106 / 48$ & 1.68 & $0.84-3.32$ & 0.14 & $111 / 156$ & 1.05 & $0.69-1.60$ & 0.83 \\
\hline$I L I R I$ & rs3917318 & $102 / 45$ & 1.138 & $0.67-1.94$ & 0.64 & $108 / 155$ & 1.07 & $0.74-1.54$ & 0.72 \\
\hline ILIB & rs3917365 & $99 / 44$ & 1.63 & $0.78-3.42$ & 0.19 & $105 / 146$ & 1.03 & $0.62-1.73$ & 0.90 \\
\hline IL6 & rs 1800797 & $104 / 43$ & 1.28 & $0.66-2.46$ & 0.46 & $110 / 155$ & 1.05 & $0.67-1.64$ & 0.83 \\
\hline & rs 2069830 & $103 / 45$ & 1.63 & $0.48-5.58$ & 0.43 & $109 / 155$ & 0.30 & $0.11-0.82$ & 0.019 \\
\hline & rs2069832 & $101 / 45$ & 0.69 & $0.35-1.35$ & 0.28 & $109 / 152$ & 0.80 & $0.51-1.26$ & 0.34 \\
\hline MMP3 & rs679620 & $103 / 46$ & 0.98 & $0.58-1.65$ & 0.93 & $110 / 157$ & 1.01 & $0.71-1.43$ & 0.97 \\
\hline
\end{tabular}

* Adjusted for age and race (African-American, Caucasian, and other). 
among African-Americans, similar ORs as found in the combined population were seen among smokers $(\mathrm{OR}=$ $1.31, \mathrm{p}=0.71$ ) and non-smokers $(\mathrm{OR}=0.38, \mathrm{p}=0.10)$, consistent with a protective effect for the $\mathrm{T}$ allele among non-smokers. For IL-6 SNP rs2069830, among both Caucasian non-smokers and smokers, the logistic regression models did not converge due to the low frequency (2\%) of the T allele.

\section{Discussion}

Our study did not demonstrate strong relationships between the inflammatory gene polymorphisms and ischemic stroke risk. Only IL6 (rs2069832) was found to be associated with stroke, and only among African-Americans. However, it did identify two polymorphisms that appear to influence stroke risk via a gene-environment interaction with cigarette smoking, IL6 rs2069830 and CD-14 rs2569190.

IL-6 plays a key role in the acute inflammatory response and in regulation of the production of acute phase proteins such as C-reactive protein $[15,16]$. It contributes to the inflammatory response by activating endothelial cells $[15,17]$ and stimulating the synthesis of fibrinogen $[15,18]$. In vivo exposure to cigarette smoke has been shown to increase the expression of proinflammatory cytokines including IL-6 [19]. Furthermore, several studies have demonstrated that IL-6 polymorphisms may mediate carotid artery intima-media wall thickness $[20,21]$, an intermediate marker of stroke risk. Our results, consistent with other studies, demonstrates that genetic variation in IL-6 may modify stroke risk [15,22], and that this increased risk may be due to synergistic effects between proinflammatory genotypes and smoking [23].

CD14 is a surface protein preferentially expressed on monocytes and macrophages that acts to bind lipopolysaccharide-binding protein (also called endotoxin). Endotoxin is a potent mediator of inflammation, and smokers have elevated plasma levels of endotoxin. Hence, it is believed that the risk of atherosclerosis from endotoxemia is increased in smokers [24]. The CD14 SNP rs2569190 is a $\mathrm{C}>\mathrm{T}$ substitution in the proximal CD14 promoter GC box at position -260 from the translation start site and results in a HaeIII restriction site [25]. The results of studies which have tried to determine which allele mediates vascular risk have been variable. The $\mathrm{T}$ allele was associated with an increased risk of MI [25-28] and two ischemic stroke subtypes including atherosclerosis of large arteries and microangiopathy [29]. Contrary to these studies, the $\mathrm{C}$ allele was associated with a higher risk of carotid plaque formation [30], and was found to act synergistically with other inflammatory SNPs to increase carotid IMT [7,9], specifically among smokers [7]. Still other studies evaluating this SNP have found no associa- tion with stroke $[31,32]$. Our results support a gene-environment association between the $\mathrm{C}$ allele and ischemic stroke risk among smokers. Our findings replicate a prior study showing an interaction with smoking and the $\mathrm{C}$ allele of CD14 SNP rs2569190 [7].

Our study has several limitations. Most notably, we only evaluated a limited number of SNPs, which were not sufficient to comprehensively evaluate stroke risk or smoking interaction for any of the genes studied. Secondly, our study did not provide any mechanistic information regarding stroke risk or protection. Specifically, we did not determine if our SNPs were associated with increased or decreased protein activity. Furthermore, our study population is relatively small and is underpowered to detect modest effects, particularly in the stroke subtype analyses. Although we have attempted to minimize phenotypic heterogeneity through identifying ischemic stroke subtypes during adjudication, we recognize that residual phenotypic heterogeneity may exist. Lastly, though we performed numerous analyses, no correction was made for multiple comparisons. This allows for the possibility that our results could be attained through chance alone, although confirming CD-14 rs2569190 as a mediator of vascular risk, and specifically among smokers of both races, makes such a false positive association less likely.

\section{Conclusion}

This study demonstrates that inflammatory gene SNPs may be associated with early-onset ischemic stroke among African-American women (ILG) and that cigarette smoking may modulate stroke risk through a gene-environment interaction (IL6 and CD14).

\section{Competing interests}

The authors declare that they have no competing interests.

\section{Authors' contributions}

All authors certify that they participated in the conceptual design of this work, the analysis of the data, and the writing of the manuscript to take public responsibility for it. All authors reviewed the final version of the manuscript and approve it for publication. JWC, OCS, and SJK participated in the writing of the initial draft. OCS participated in the genotyping. JWC OCS, MAW, BJS, MJS, MD, LS, NZ, and SJK participated in DNA and data collection. JWC, DWB, WHG, JRO, BDM, JDS, and LJR participated in the data analysis. All authors provided critiques of the final manuscript.

The findings and conclusions in this report are those of the authors and do not necessarily represent the official position of the Centers for Disease Control and Prevention. 


\section{Availability \& requirements http://www.ncbi.nlm.nih.gov/entrez/ query.fcgi? $\mathrm{CMD}=$ search $\& \mathrm{DB}=$ snp}

\section{http://www.ncbi.nlm.nih.gov/Genbank/index.html}

\section{Acknowledgements}

We are indebted to the following members of the Stroke Prevention in Young Women research team for their dedication: Esther Berrent, Kathleen Caubo, Julia Clark, Mohammed Huq, Ann Maher, Tamar Pair, and Mary Simmons.

The authors would like to acknowledge the assistance of the following individuals who have sponsored the Stroke Prevention in Young Women Study at their institution: Clifford Andrew, MD; Merrill Ansher, Brian Avin, MD; MD; Harjit Bajaj, MD; Robert Baumann, MD; Nicholas Buendia, MD, Young Ja Cho, MD; Kevin Crutchfield, MD; Terry Detrich, MD; Mohammed Dughly, MD; Boyd Dwyer, MD; Jerold Fleishman, MD; Stuart Goodman, MD, PhD; Adrian Goldszmidt, MD; Kalpana Hari Hall, MD; Walid Kamsheh, MD; John Kelly, MD; Harry Kerasidis, MD; Mehrullah Khan, MD; Ramesh Khurana, MD; Ruediger Kratz MD; Somchai Laowattana, MD; William Leahy, MD; Alan Levitt, MD; Bruce Lobar, MD; Paul Melnick, MD; Harshad Mody, MD; Seth Morgan, MD; Howard Moses, MD; Francis Mwaisela, MD; Sivarama Nandipati, MD; Maciej Poltorak, MD; Thaddeus Pula, MD; Phillip Pulaski, MD; Neelupali Reddy, MD; Perry Richardson, MD; Solomon Robbins, MD; Michael Sellman, MD, PhD; Barney Stern, MD; Jack Syme, MD; Richard Taylor, MD; Dean Tippett, MD; Michael Weinrich, MD; Roger Weir, MD; Richard Weisman, MD; Laurence Whicker, MD; Robert Wityk, MD; James Yan, MD and Manuel Yepes, MD.

In addition, the study could not have been completed without the support from the administration and medical records staff at the following institutions: In Maryland: Anne Arundel Medical Center, Bon Secours Hospital, Calvert Memorial Hospital, Carroll County General Hospital, Chester River Hospital, Civista Medical Center, Department of Veterans Affairs Medical Center in Baltimore, Doctors Community Hospital, Dorchester Hospital, Franklin Square Hospital Center, Frederick Memorial Hospital, Good Samaritan Hospital, Greater Baltimore Medical Center, Harbor Hospital Center, Hartford Memorial Hospital, Holy Cross Hospital, Howard County General Hospital, Johns Hopkins Bayview, The Johns Hopkins Hospital, Kernan Hospital, Laurel Regional Hospital, Maryland General Hospital, McCready Memorial Hospital, Memorial Hospital at Easton, Mercy Medical Center, Montgomery General Hospital, North Arundel Hospital, Northwest Hospital Center, Peninsula Regional Medical Center, Prince George's Hospital Center, Saint Agnes Hospital, Saint Joseph Medical Center, Saint Mary's Hospital, Shady Grove Adventist Hospital, Sinai Hospital of Baltimore, Southern Maryland Hospital Center, Suburban Hospital, Union Hospital Cecil County, The Union Memorial Hospital, University of Maryland Medical System, Upper Chesapeake Medical Center, Washington Adventist Hospital and Washington County Hospital; in Washington DC: The George Washington University Medical Center; Georgetown University Hospital; Hadley Memorial Hospital; Howard University Hospital; National Rehabilitation Hospital; Providence Hospital; Sibley Memorial Hospital; and the Washington Hospital Center; in Pennsylvania: Gettysburg Hospital.

Funding acknowledgments: Dr. Cole was supported in part by the Department of Veterans Affairs, Baltimore, Office of Research and Development, Medical Research Service; the Department of Veterans Affairs Stroke Research Enhancement Award Program; the University of Maryland General Clinical Research Center (Grant M0I RR I6500I), General Clinical
Research Centers Program, National Center for Research Resources, NIH, and; an American Heart Association Beginning Grant-in-Aid (Grant 0665352U). Dr. Kittner was supported in part by the Department of Veterans Affairs, Baltimore, Office of Research and Development, Medical Research Service, and Geriatrics Research, Education and Clinical Center, and Stroke Research Enhancement Award Program; a Cooperative Agreement with the Division of Adult and Community Health, Centers for Disease Control and Prevention; the National Institute of Neurological Disorders and Stroke and the NIH Office of Research on Women's Health; the National Institute on Aging Pepper Center (Grant P60 I2583); and the University of Maryland General Clinical Research Center (Grant MOI RR 16500I), General Clinical Research Centers Program, National Center for Research Resources, NIH. Dr. Sorkin was supported by the Baltimore VA Medical Center Geriatrics Research, Education, and Clinical Center; the University of Maryland Claude D. Pepper Older Americans Independence Center; the Clinical Nutrition Research Unit of the University of Maryland, and; the Baltimore VA Medical Center, Center for Excellence in Robotics.

\section{References}

I. Ross R: Atherosclerosis - an inflammatory disease. N Engl J Med 1999, 340:II5-126.

2. Ambrose JA, Barua RS: The pathophysiology of cigarette smoking and cardiovascular disease: an update. J Am Coll Cardiol 2004, 43: 1731- 1737.

3. Benowitz NL: Cigarette smoking and cardiovascular disease: pathophysiology and implications for treatment. Prog Cardiovasc Dis 2003, 46:91-III.

4. Craig WY, Palomaki GE, Haddow JE: Cigarette smoking and serum lipid and lipoprotein concentrations: An analysis of published data. BM] $1989,298: 784-788$

5. Rival J, Riddle JM, Stein PD: Effects of chronic smoking on platelet function. Thromb Res 1987, 45:75-85.

6. Perlstein TS, Lee RT: Smoking, metalloproteinases, and vascular disease. Arterioscler Thromb Vasc Biol 2006, 26:250-6.

7. Jerrard-Dunne P, Sitzer M, Risley P, Buehler A, von Kegler S, Markus HS: Inflammatory Gene Load Is Associated With Enhanced Inflammation and Early Carotid Atherosclerosis in Smokers. Stroke 2004, 35:2438-43.

8. Humphries SE, Morgan L: Genetic risk factors for stroke and carotid atherosclerosis: insights into pathophysiology from candidate gene approaches. Lancet Neurol 2004, 3:227-236.

9. Markus HS, Labrum R, Bevan S, Reindl M, Egger G, Wiedermann CJ, Xu Q, Kiechl S, Willeit J: Genetic and acquired inflammatory conditions are synergistically associated with early carotid atherosclerosis. Stroke 2006, 37:2253-9.

10. de Maat MP, Pietersma A, Kofflard M, Sluiter W, Kluft C: Association of plasma fibrinogen levels with coronary artery disease, smoking and inflammatory markers. Atherosclerosis 1996, | 2 | : |85-9|.

II. Johnson CJ, Kittner SJ, McCarter RJ, Sloan MA, Stern BJ, Buchholz D, Price TR: Interrater reliability of an etiologic classification of ischemic stroke. Stroke 1995, 26:46-5I.

12. Kittner SJ, Stern BJ, Feeser BR, Hebel R, Nagey DA, Buchholz DW, Earley CJ, Johnson CJ, Macko RF, Sloan MA, Wityk RJ, Wozniak MA: Pregnancy and the risk of stroke. N Engl J Med 1996, 335:768-774.

13. Kittner SJ, Stern BJ, Wozniak M, Buchholz DW, Earley CJ, Feeser BR, Johnson CJ, Macko RF, McCarter RJ, Price TR, Sherwin R, Sloan MA, Wityk RJ: Cerebral infarction in young adults: the BaltimoreWashington Cooperative Young Stroke Study. Neurology 1998, 50:890-4.

14. Meschia JF, Brown RD Jr, Brott TG, Chukwudelunzu FE, Hardy J, Rich SS: The Siblings With Ischemic Stroke Study (SWISS) protocol. BMC Med Genet 2002, 3:I.

I5. Yamada Y, Metoki N, Yoshida H, Satoh K, Ichihara S, Kato K, Kameyama T, Yokoi K, Matsuo H, Segawa T, Watanabe S, Nozawa Y: Genetic risk for ischemic and hemorrhagic stroke. Arterioscler Thromb Vasc Biol 2006, 26: 1920-5.

16. Heinrich PC, Castell JV, Andus T: IL-6 and the acute phase response. Biochem J 1990, 265:621-636.

17. Romano M, Sironi M, Toniatti C, Polentarutti N, Fruscella P, Ghezzi P, Faggioni R, Luini W, van Hinsbergh V, Sozzani S, Bussolino F, Poli 
V, Ciliberto G, Mantovani A: Role of IL-6 and its soluble receptor in induction of chemokines and leukocyte recruitment. Immunity 1997, 6:315-325.

18. Dalmon J, Laurent M, Courtois G: The human $\beta$ fibrinogen promoter contains a hepatocyte nuclear factor I-dependent IL6-responsive element. Mol Cell Biol 1993, I3: I I83-93.

19. Orosz Z, Csiszar A, Labinskyy N, Smith K, Kaminski PM, Ferdinandy P, Wolin MS, Rivera A, Ungvari Z: Cigarette smoke-induced proinflammatory alterations in the endothelial phenotype: role of NAD(P)H oxidase activation. Am J Physiol Heart Circ Physiol 2007, 292(I):HI 19-20.

20. Rundek T, Elkind MS, Pittman J, Boden-Albala B, Martin S, Humphries $\mathrm{SE}$, Juo SH, Sacco RL: Carotid intima-media thickness is associated with allelic variants of stromelysin-I, IL-6, and hepatic lipase genes: the Northern Manhattan Prospective Cohort Study. Stroke 2002, 33:1420-1423.

21. Rauramaa R, Vaisanen SB, Luong LA, Schmidt-Trucksass A, Penttila IM, Bouchard C, Toyry J, Humphries SE: Stromelysin-I and IL-6 gene promoter polymorphisms are determinants of asymptomatic carotid artery atherosclerosis. Arterioscler Thromb Vasc Biol 2000, 20:2657-62.

22. Balding J, Livingstone WJ, Pittock SJ, Mynett-Johnson L, Ahern T, Hodgson A, Smith OP: The IL-6 G-174C polymorphism may be associated with ischaemic stroke in patients without a history of hypertension. Ir J Med Sci 2004, 173:200-3.

23. Flex A, Gaetani E, Papaleo P, Straface G, Proia AS, Pecorini G, Tondi $P$, Pola $P$, Pola R: Proinflammatory genetic profiles in subjects with history of ischemic stroke. Stroke 2004, 35:2270-5.

24. Risley P, Jerrard-Dunne P, Sitzer M, Buehler A, von Kegler S, Markus HS: Promoter polymorphism in the endotoxin receptor (CDI4) is associated with increased carotid atherosclerosis only in smokers: the Carotid Atherosclerosis Progression Study (CAPS). Stroke 2003, 34:600-4.

25. Hubacek JA, Rothe G, Pit'ha J, Škodová Z, Stanek V, Poledne R, Schmitz G: C(-260)-->T polymorphism in the promoter of the CDI 4 monocyte receptor gene as a risk factor for myocardial infarction. Circulation 1999, 99:3218-20.

26. Unkelbach K, Gardemann A, Kostrzewa M, Philipp M, Tillmanns H, Haberbosch WA: New promoter polymorphism in the gene of lipopolysaccharide receptor CDI4 is associated with expired myocardial infarction in patients with low atherosclerotic risk profile. Arterioscler Thromb Vasc Biol 1999, 19:932-8.

27. Hohda S, Kimura A, Sasaoka T, Hayashi T, Ueda K, Yasunami M, Okabe M, Fukuta N, Kurosawa T, Izumi T: Association study of CDI 4 polymorphism with myocardial infarction in a Japanese population. Jpn Heart J 2003, 44:6I3-22.

28. Porsch-Ozcurumez M, Hucke J, Westphal S, Hubacek JA, Schmitz G, Luley C: A post-hoc analysis on the CDI 4 C (-260)T promoter polymorphism and coronary heart disease. Physiol Res 2006 in press.

29. Lichy C, Meiser H, Grond-Ginsbach C, Buggle F, Dorfer C, Grau A: Lipopolysaccharide receptor CDI 4 polymorphism and risk of stroke in a South-German population. I Neurol 2002, 249:82।-3.

30. Hung J, McQuillan BM, Chapman CM, Thompson PL, Beilby JP: Promoter polymorphism of the gene for CDI4 receptor is not associated with sub-clinical carotid atherosclerosis in a community population. Eur J Cardiovasc Prev Rehabil 2004, I I:344-9.

31. Ito D, Murata M, Tanashi N, Sato H, Sonoda A, Saito I, Watanabe K, Fukuuchi Y: Polymorphism in the promotor of lipopolysaccharide receptor $\mathrm{CDI} 4$ and ischemic cerebrovascular disease. Stroke 2000, 3I:266 I-4.

32. Zee RY, Bates $D$, Ridker PM: A prospective evaluation of the CDI4 and CDI8 gene polymorphisms and risk of stroke. Stroke 2002, 33:892-5.

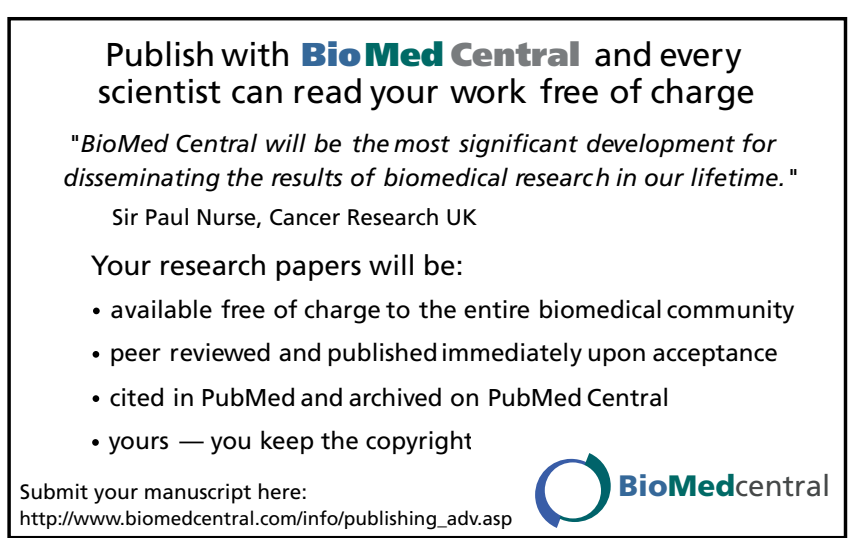

